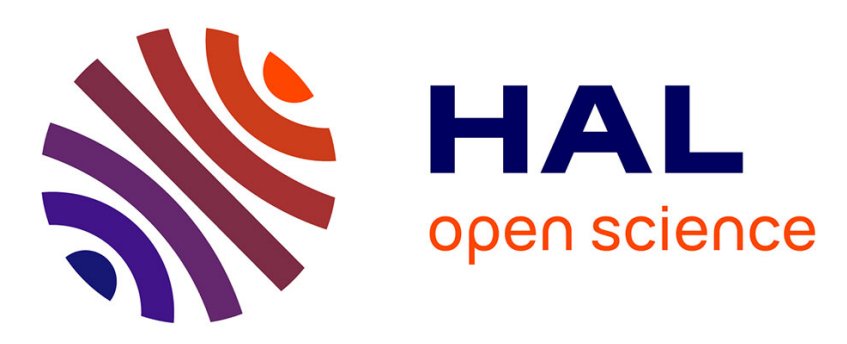

\title{
Multi-scale electrical response of silicon nitride/multi-walled carbon nanotubes composites
}

J. González-Julián, Y. Iglesias, A.C. Caballero, M. Belmonte, L. Garzón, C. Ocal, P. Miranzo, M.I. Osendi

\section{- To cite this version:}

J. González-Julián, Y. Iglesias, A.C. Caballero, M. Belmonte, L. Garzón, et al.. Multi-scale electrical response of silicon nitride/multi-walled carbon nanotubes composites. Composites Science and Technology, 2010, 71 (1), pp.60. 10.1016/j.compscitech.2010.10.004 . hal-00702317

\section{HAL Id: hal-00702317 https://hal.science/hal-00702317}

Submitted on 30 May 2012

HAL is a multi-disciplinary open access archive for the deposit and dissemination of scientific research documents, whether they are published or not. The documents may come from teaching and research institutions in France or abroad, or from public or private research centers.
L'archive ouverte pluridisciplinaire HAL, est destinée au dépôt et à la diffusion de documents scientifiques de niveau recherche, publiés ou non, émanant des établissements d'enseignement et de recherche français ou étrangers, des laboratoires publics ou privés. 


\section{Accepted Manuscript}

Multi-scale electrical response of silicon nitride/multi-walled carbon nanotubes composites

J. González-Julián, Y. Iglesias, A.C. Caballero, M. Belmonte, L. Garzón, C. Ocal, P. Miranzo, M.I. Osendi

PII: S0266-3538(10)00387-8

DOI: 10.1016/j.compscitech.2010.10.004

Reference: CSTE 4823

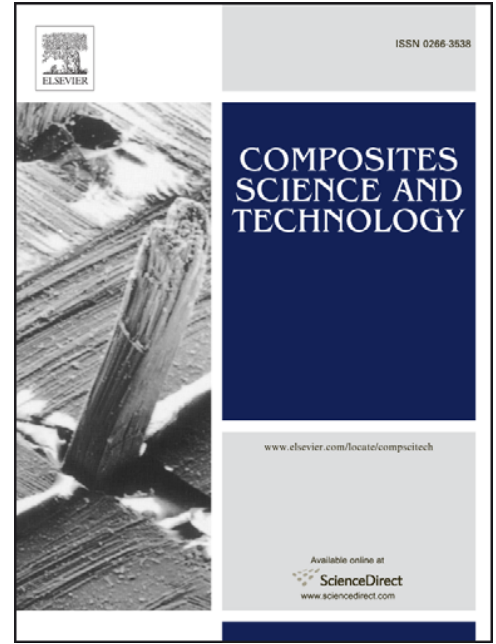

To appear in:

Composites Science and Technology

Received Date:

19 January 2010

Revised Date:

1 October 2010

Accepted Date:

7 October 2010

Please cite this article as: González-Julián, J., Iglesias, Y., Caballero, A.C., Belmonte, M., Garzón, L., Ocal, C., Miranzo, P., Osendi, M.I., Multi-scale electrical response of silicon nitride/multi-walled carbon nanotubes composites, Composites Science and Technology (2010), doi: 10.1016/j.compscitech.2010.10.004

This is a PDF file of an unedited manuscript that has been accepted for publication. As a service to our customers we are providing this early version of the manuscript. The manuscript will undergo copyediting, typesetting, and review of the resulting proof before it is published in its final form. Please note that during the production process errors may be discovered which could affect the content, and all legal disclaimers that apply to the journal pertain. 


\title{
Multi-scale electrical response of silicon nitride/multi-walled carbon nanotubes
}

\section{composites}

J. González-Julián ${ }^{\mathrm{a}}$, Y. Iglesias ${ }^{\mathrm{a}}$, A. C. Caballero ${ }^{\mathrm{a}}$, M. Belmonte ${ }^{\mathrm{a} *}$, L. Garzón ${ }^{\mathrm{b}}$, C. Ocal ${ }^{\mathrm{b}}$, P. Miranzo $^{\mathrm{a}}$, M. I. Osendi ${ }^{\mathrm{a}}$

${ }^{\mathrm{a}}$ Institute of Ceramics and Glass, CSIC. Campus Cantoblanco. C/ Kelsen, 5. 28049 Madrid. Spain

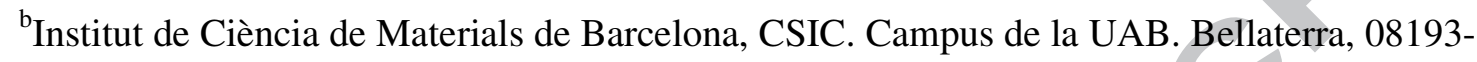
Cerdanyola del Vallès. Spain

\begin{abstract}
Dense silicon nitride $\left(\mathrm{Si}_{3} \mathrm{~N}_{4}\right)$ composites with various amounts $(0-8.6 \mathrm{vol} \%)$ of multiwalled carbon nanotubes (MWCNTs) are electrically characterised by combining macroscopic dc-ac and nanoscale conductive scanning force microscopy (C-SFM) measurements. In this way, a coherent picture of the dominant charge transport mechanisms in $\mathrm{Si}_{3} \mathrm{~N}_{4} / \mathrm{MWCNTs}$ composites is presented. A raise of more than ten orders of magnitude in the electrical dc conductivity compared to the blank specimen is measured for MWCNTs contents above 0.9 vol\%. Semiconductor and metallic-like behaviours are observed depending on both the temperature and the MWCNTs content. Macroscopic measurements are further supported at the nanoscale by means of C-SFM. The metallic-type conduction is associated to charge transporting along the nanotube shells, whereas the semiconductor behaviour is linked to hopping conduction across nanotube-nanotube contacts and across intrinsic defect clusters within the nanotubes.
\end{abstract}

\footnotetext{
* Corresponding author. Tel.: +34 917355863; fax: +34 917355843

E-mail address: mbelmonte@icv.csic.es (M. Belmonte).
} 
Keywords: A. Carbon nanotubes; A. Ceramic-matrix composites (CMCs); B. Electrical properties; D. Atomic force microscopy (AFM); Silicon nitride.

\section{Introduction}

Silicon nitride $\left(\mathrm{Si}_{3} \mathrm{~N}_{4}\right)$ based materials are well known for their extraordinary strength and hardness at high temperatures that make them suitable for applications under wear conditions, like cutting tools or ball bearings [1]. The full potentiality of these materials is only partially achieved by the difficulty inherent to their machining. Recent works [2,3] have shown the possibility of the efficient electric discharge machining (EDM) for $\mathrm{Si}_{3} \mathrm{~N}_{4}$ materials when adding an electric conductive second phase, such as TiN [2] or $\mathrm{MoSi}_{2}$ [3]. The amount of such second phases required to get a reasonable reduction in resistivity was around 30 vol\%. Besides, it has been pointed out that problems caused by static electricity in $\mathrm{Si}_{3} \mathrm{~N}_{4}$ bearings could be avoided by the addition of highly conducting carbon nanotubes (CNTs) [4]. Therefore, the change from highly electric insulator to conductor in $\mathrm{Si}_{3} \mathrm{~N}_{4}$ materials without degrading other properties would have great technological interest.

The step raise in electrical conductivity is the common trend observed in ceramic/CNTs composites once percolation of the CNTs network is achieved [4-11]. Due to their high aspect ratio, quite low percolation thresholds, between 0.64 and 3.0 vol\%, have been reported for ceramic/CNTs composites [7-10]. Conductivity values after percolation seem to depend much on the CNT type and purity as well as on the composite processing procedure, which may damage the nanotubes. For single-walled carbon nanotubes (SWCNTs) containing alumina composites, electrical conductivities $(\sigma)$ of $10^{3} \mathrm{~S} \cdot \mathrm{m}^{-1}$ have been reported [5], whereas in composites containing multi-walled carbon nanotubes (MWCNTs) much lower values, in the order of $10 \mathrm{~S} \cdot \mathrm{m}^{-1}$, have been attained [4,6-9]. For $\mathrm{MgAl}_{2} \mathrm{O}_{4} / \mathrm{SWCNTs}$ composites processed by in-situ catalytic chemical vapour deposition (CVD) [10], $\sigma$ was well fitted by the scaling law of the percolation theory as $\sigma=\mathrm{k}\left(\mathrm{p}-\mathrm{p}_{\mathrm{c}}\right)^{\mathrm{t}}$, giving a percolation 
threshold, $\mathrm{p}_{\mathrm{c}}$, of 0.64 vol\% and an exponent, $\mathrm{t}$, of 1.73. In $\mathrm{Si}_{3} \mathrm{~N}_{4} / \mathrm{MWCNTs}$ composites, electrical conductivity values about $10 \mathrm{~S} \cdot \mathrm{m}^{-1}$ for nanotube contents between 1 and $5 \mathrm{wt} \%$ have been reported $[4,6]$, but values for $\mathrm{p}_{\mathrm{c}}$ have not been given yet.

In the present work, we describe the electrical properties of $\mathrm{Si}_{3} \mathrm{~N}_{4}$ with various contents of MWCNTs in dc and ac conditions for a wide temperature range, highlighting the effect of nanotube content and their connection within the network. The local electrical response of the composites is also analyzed and correlated with their nanostructure by means of conductive scanning force microscopy (C-SFM).

\section{Experimental procedure}

$\mathrm{Si}_{3} \mathrm{~N}_{4}$ materials containing MWCNTs, in concentrations ranging from 0.9 to $8.6 \mathrm{vol} \%$, were prepared as described elsewhere [12]. In short, CVD synthesized MWCNTs of $30 \mathrm{~nm}$ diameter and 1-5 $\mu \mathrm{m}$ length, according to the supplier (Nanolab Inc., USA), were thoroughly mixed with $\mathrm{Si}_{3} \mathrm{~N}_{4}$ (SN-E10, UBE Industries, Japan) plus liquid forming sintering additives, 2 wt $\%$ of $\mathrm{Al}_{2} \mathrm{O}_{3}$ (SM8, Baikowski Chimie, France) and $5 \mathrm{wt} \%$ of $\mathrm{Y}_{2} \mathrm{O}_{3}$ (Grade C, H.C. Starck GmbH \& Co., Germany). Compositions were spark plasma sintered (Dr. Sinter, SPS-510CE, Japan) at $1585^{\circ} \mathrm{C}$ for $5 \mathrm{~min}$ in vacuum (6 Pa), applying a pressure of $50 \mathrm{MPa}$. Specimens were discs of $20 \mathrm{~mm}$ diameter and about $3 \mathrm{~mm}$ thick. A blank sample without nanotubes was equally processed for comparison. All specimens had densities above $99 \%$ of the theoretical, good nanotube dispersion and no evidence of degradation, as previously reported [12]. Microstructures on both polished and plasma etched $\left(\mathrm{CF}_{4} / 5 \mathrm{vol} \% \mathrm{O}_{2}\right.$ at $100 \mathrm{~W}$ for $\left.40 \mathrm{~s}\right)$ and fracture specimens containing MWCNTs were observed using a field emission scanning electron microscope (FESEM, Hitachi S-4700, Japan). Besides, samples were also prepared for observation in the transmission electron microscope (TEM, 200kV JEOL JEM 2000 FX) following usual cutting, dimpling and ion thinning procedures. 
Micro-Raman spectra of the original MWCNTs and the composites were taken using the $540 \mathrm{~nm}$ laser wavelength excitation (In Via, Renishaw equipment, UK).

For the macroscopic electrical characterization, either two or four probe method was used depending on the electrical conductivity level initially measured. Resistivity under dc conditions was calculated from the current density versus electric field curves measured in a Keithley Sourcemeter 2410 model. For the ac characterization an Agilent 4294A Precision Impedance analyzer was employed scanning the frequency range $10-10^{7} \mathrm{~Hz}$. Measurements at different temperatures, from 273 to $573 \mathrm{~K}$ in $50 \mathrm{~K}$ steps and at $2 \mathrm{~K} \cdot \mathrm{min}^{-1}$ heating rate, were carried out in a home-made furnace that can be fitted to each probe configuration.

Scanning force microscopy (SFM) measurements were performed under low humidity conditions (2\% RH, obtained in a $\mathrm{N}_{2}$ atmosphere) using a commercial head and software from Nanotec. [13]. Commercial silicon $\mathrm{Cr} / \mathrm{Pt}$ coated probes and boron-doped diamond probes with force constants $\mathrm{k}=0.2$ and $3.0 \mathrm{~N} \cdot \mathrm{m}^{-1}$ were used for both morphological and conductive SFM measurements. To check tip-sample conditions, the adhesion force was systematically determined from force versus distance curves prior to and after each conductivity experiment. The conducting tip was placed in direct contact with the sample, under controlled load, i.e. by using a normal force feedback, and the current was measured between tip and sample. The sample was always grounded and the voltage was applied to the tip $\left(\mathrm{V}_{\text {tip }}\right)$. Direct electric contact to ground was established through a metallic clamp attached at the sample border. We note that the ability to control the applied load permits avoiding any undesirable tip-induced effect, separating and controlling the mechanical response of the system under study. The conducting response of the sample surface was obtained by following different strategies [14]: i) simultaneously acquiring topographic images $\mathrm{z}(\mathrm{x}, \mathrm{y})$ and current maps I (x,y) over a given region at a given voltage, and ii) acquiring I-V characteristics curves at selected (x,y) locations on the surface. I-V curves were performed at least on 5 different regions for each sample and, within each region; 30-40 I-V curves were recorded. 


\section{Results and discussion}

According to previous results of present authors [12], the processing route used for these $\mathrm{Si}_{3} \mathrm{~N}_{4} / \mathrm{MWCNT}$ composites produces reasonably good dispersion of the MWCNTs within the $\mathrm{Si}_{3} \mathrm{~N}_{4}$ matrix, as FESEM observations of fractured surfaces revealed [12]. Besides, the spark plasma sintering conditions allow high relative densities, $\geq 99.0 \%$, while avoid nanotubes degradation, as micro-Raman spectroscopy data confirmed by showing similar intensity ratios for the characteristics bands of MWCNTs, i.e. D/G and G'/G [12], in both the composites and original nanotubes.

TEM observations indicate that MWCNTs are bent and twisted at $\mathrm{Si}_{3} \mathrm{~N}_{4}$ grain boundaries (Fig. 1). Then, we can expect that the bulk electrical transport behaviour of the $\mathrm{Si}_{3} \mathrm{~N}_{4} / \mathrm{MWCNT}$ composites could be controlled by the nanotubes network but not by the nonconductive $\mathrm{Si}_{3} \mathrm{~N}_{4}$ matrix.

Figure 2 shows the de electrical conductivity as a function of the MWCNTs content. The value in the plot for the blank $\mathrm{Si}_{3} \mathrm{~N}_{4}$ corresponds to the detection limit of our experimental set-up, $10^{-13} \mathrm{~S} \cdot \mathrm{m}^{-1}$; therefore, the real conductivity must be even lower. For the 0.9 vol\% MWCNTs specimen, a sharp conductivity increase of more than ten orders of magnitude $\left(4 \times 10^{-2} \mathrm{~S} \cdot \mathrm{m}^{-1}\right)$ is registered as compared to the reference $\mathrm{Si}_{3} \mathrm{~N}_{4}$ specimen, which infers a $\mathrm{p}_{\mathrm{c}}<0.9 \mathrm{vol} \%$. For the samples with MWCNTs contents of 1.8 and $5.3 \mathrm{vol} \%$, the conductivity steadily increases reaching values of 0.3 and $14 \mathrm{~S} \cdot \mathrm{m}^{-1}$, respectively, and levels off at a content of $8.6 \mathrm{vol} \%$ to a saturation value of $17 \mathrm{~S} \cdot \mathrm{m}^{-1}$. Similar rises in electrical conductivity have been reported but for higher MWCNTs contents, $1.8 \mathrm{wt} \%$ [4] and $3.0 \mathrm{wt} \%$ [6] (about 3 and $5 \mathrm{vol} \%$, respectively), for two different $\mathrm{Si}_{3} \mathrm{~N}_{4} / \mathrm{MWCNTs}$ composites sintered by hot pressing at higher temperatures than in the present work. The scattering in the reported percolation threshold and in electrical conductivity data [4-11] are commonly due to differences in CNTs dimensions and type (SWCNT or MWCNT), their dispersion degree in 
the composite and the sintering temperature, as exposure to high temperatures may damage the nanotubes. For ceramic composites, percolation threshold values mostly lie between 0.64 vol\% $[8,10]$ and 0.80 vol\% [9].

As it is shown in Figure 2 for present composites, $\sigma$ data at room temperature fit the scaling law using same parameters as Rul et al.,[10] i.e., $\mathrm{p}_{\mathrm{c}}$ of $0.64 \mathrm{vol} \%$ and $\mathrm{t}$ of 1.73 . The value of $t$ lower than the characteristic of a tri-dimensional network $(t=2.0)$ was associated to a fluctuation induced tunnelling mechanism $[9,10,15]$, where thermally induced hopping transport between the CNTs separated by an insulating barrier dominates the conductivity behaviour. Monte Carlo simulations [15] points out that the tunnelling resistance caused by the insulating barrier between nanotubes or their aggregates plays a dominant role in the effective electrical conductivity of nanotube-based nanocomposites. According to those simulations, the tunnelling resistivity augments with increasing dielectric constant of the insulating matrix film between nanotubes, but this does not seem determinant because of the small differences in dielectric constants of these types of ceramics [16], explaining the similar percolation thresholds observed for different nanotube-ceramic composites [8-10].

The temperature dependence of the dc current-voltage curves of the composites with the lowest and highest MWCNTs content (Fig. 3), i.e., specimens with 0.9 and 8.6 vol\% of MWCNTs, reveals notable differences in their electrical responses. For the 0.9 vol\% composite (Fig. 3a), the I-V curves are non-linear in the whole range of measured temperatures. It should also be noticed that the electrical conductivity increases with temperature, which is consistent with classical negative temperature coefficient (NTC) type semiconductor behaviour $[17,18]$. The origin of the non-ohmic behaviour is the existence of potential barriers that control the charge transport, which, in CNT containing composites, may form at nanotube-nanotube contacts as well as in regions within nanotubes showing high concentration of atomic defects. The composites microstructure can be described by the brick layer model [19], where the conducting MWCNTs network is found at grain boundaries (Fig. 
1) surrounding the much less conductive $\mathrm{Si}_{3} \mathrm{~N}_{4}$ matrix. This agrees with the scenario also assumed for $\mathrm{Al}_{2} \mathrm{O}_{3} / \mathrm{MWCNTs}$ composites [20], described as an insulating matrix with large interconnected conducting regions at the grain boundaries in which potential barriers are built-up. On the other hand, the composite with 8.6 vol\% MWCNTs (Fig. 3b) exhibits a linear current-voltage response at temperatures up to $423 \mathrm{~K}$ changing to a non-linear dependence at higher temperatures. Note also that up to $373 \mathrm{~K}$, a small positive temperature coefficient (PTC) behaviour is measured, in accordance with the relevant metallic-like conduction mechanism. Furthermore, a slight increase in resistivity is detected at $523 \mathrm{~K}$. These results lead us to infer that the electrical transport in these materials is a balance between semiconductor and metallic-like mechanisms, whose weights depend on both the temperature and the MWCNTs content. It should be noticed that both kinds of charge transport mechanisms have been reported for individual carbon nanotubes [21] and buckypapers [22]. The change of the electrical response observed for the highest MWCNTs content points out to the possible origin of the potential barriers. Increasing the amount of MWCNTs will decrease the intertube spacing, improving the connectivity of the conducting nanotube network, reducing the thickness of the insulating film and favouring the tunnelling penetration of electrons. Consequently, at low MWCNTs content the contact resistance associated to the insulating film plays a dominant role in the effective electrical conductivity, whereas intrinsic defect clusters within the nanotubes becomes competitive in composites with high MWCNTs contents. Then, the changes observed in the temperature dependence of the electrical conductivity, are determined by the intrinsic electronic properties of MCWNTs.

For gaining some insight of the different conduction mechanisms in these composites, ac impedance spectroscopy measurements versus temperature were done in the 0.9 and 8.6 vol\% MWCNTs composites (Fig. 4). According to the proposed brick layer model, where the conductive phase is the grain boundary one, the impedance semicircles bring information only of the MWCNT grain boundary phase. The insulating character of the $\mathrm{Si}_{3} \mathrm{~N}_{4}$ matrix is 
corroborated by measurements in the $\mathrm{Si}_{3} \mathrm{~N}_{4}$ blank specimen, as no impedance signal could be detected up to $1173 \mathrm{~K}$ (detection limit of the system is $10^{7} \Omega$ ). As seen in Fig. 4a, for the specimen with the lowest nanotube content only one R-C circuit is needed to fit the arc, the dielectric relaxation time being in the order of $10^{-6} \mathrm{~s}$ and slightly decreasing with temperature. Conversely, the ac electrical response up to $423 \mathrm{~K}$ of the specimen with 8.6 vol\% of MWCNTs (Fig. 4b) can be fitted by two series of R-C parallel circuits, whereas above that temperature a single R-C parallel circuit describes the response of this material. The relaxation times for the two R-C parallel circuits are $1.3 \times 10^{-6} \mathrm{~s}$ and $1.4 \times 10^{-7} \mathrm{~s}$. The latter decreases with temperature down to $9.8 \times 10^{-8} \mathrm{~s}$ and above $423 \mathrm{~K}$ the arc vanishes. Zhao et al. [23] reported relaxation times of $8 \times 10^{-8} \mathrm{~s}$ for nanotube ropes of SWCNTs and MWCNTs. Therefore, the smallest relaxation time $\left(\sim 10^{-7} \mathrm{~s}\right)$ might be related to the formation of a nanotube bundle network. At $523 \mathrm{~K}$ a significant increase in resistivity is measured.

To get experimental evidences of the charge transport mechanisms in $\mathrm{Si}_{3} \mathrm{~N}_{4} / \mathrm{MWCNTs}$ composites, the local electrical response in relation to the microstructure of the composites was investigated by C-SFM. Low magnification simultaneously acquired topographic images and current maps (at $1 \mathrm{~V}$ ) are shown in Figure 5 for samples with 0.9 vol\% (Figs. 5a ,b), just above the percolation limit, and 5.3 vol\% of MWCNTs (Figs. $5 \mathrm{c}, \mathrm{d}$ ), that's it, in the plateau conductivity regime.

We first note that the surface morphology is extremely flat, as corresponds to a thoroughly polished specimen, except at the grain boundaries emerging at the surface, which are viewed as topographic holes. The flat regions do not show any detectable current, as expected from the insulating character of the $\mathrm{Si}_{3} \mathrm{~N}_{4}$ grains. However, for both specimens, electrical conduction is clearly observed at the hole grain boundary regions, exactly where the nanotubes are located as observed in the TEM micrograph (Fig. 1). In addition, note that, some nanotubes outcrop at the exposed grain boundaries (Fig. 6). The outcropping is better 
detected on the fracture surfaces (Fig. 6b), as the plasma etching process, necessary for revealing the $\mathrm{Si}_{3} \mathrm{~N}_{4}$ microstructure at the FESEM, damages the MWCNTs (Fig. 6a).

Provided that the electrical contact (tip counter electrode) is established by direct contact of a metallic clamp at the sample border, the fact of measuring current with the $\mathrm{C}$ SFM indicates that the electrical current flows between the tip-sample contact and the grounded clamp all along the nanotubes. As a result, the MWCNTs must be interconnected forming a network that extends at least over several millimetres (tip to clamp distance). Such a percolated network of nanotubes is confirmed then as the main path for electrical conduction. Further valuable information can be still obtained from the C-SFM data. On one hand, as it can be seen comparing the current maps of the composites with low and high MWCNTs contents (Fig. 5), lower current is detected for the 0.9 vol\% case. Moreover, at this low magnification, the conduction detected at the outcropping nanotubes looks like a spikelike signal. The reason has been revealed by magnified images at specific boundaries (Fig. 7). Interestingly, the current is detected at the perimeter of small $(\sim 50-100 \mathrm{~nm})$ circular contours (Fig. 7a) that are compatible with the radial dimensions of the MWCNTs. Though influenced by the unknown tip-nanotube contact resistance, I-V curves at these locations have a linear behaviour typical for a metallic-like conduction (Fig. 7b). To make clearer the correspondence between the nano-structured relief and the local electric conduction, the merged topography plus C-SFM image is presented in Fig. 7c. The result is plain; noticeably, the current is measured only at the external multi-wall shell of the nanotubes. As far as we know, this is the first experimental evidence that current is confined to the outermost layers as models predict [24,25]. In fact, a bias dependence of the conductance in MWCNTs has been ascertained by Tsukagoshi et al. [25], being the main conduction layer at low-bias voltage (0$0.1 \mathrm{~V}$ ) the outermost layer; whereas a few layers would contribute to the current conduction for higher-bias voltage (about $2 \mathrm{~V}$ ). 
At the holes, bent nanotubes bundles also emerge to the surface as small sheets of the MWCNTs network. They are observed lying on the surface nearby the grain boundaries as patches with two different electrical conductivities and I-V responses. This is illustrated in the current map of Figure 8 taken at $\mathrm{V}_{\text {tip }}=1 \mathrm{~V}$. As can be seen in the current profile I (x) (Fig. $8 b$ ), zones with different brightness present differences in current of more than one order of magnitude, pointing out different conduction mechanisms, which are corroborated by the I-V characteristic curves. The regions showing higher current levels (Fig. 8d) present I-V ohmic linear behaviour whereas the regions of low current values present non-ohmic I-V responses (Fig. 8c). The conducting circular contours described above (Fig. 7) were seen in the high conductivity ohmic regions placed at the holes, but never detected in the low conductivity regions (Fig. 8a). At these less conducting locations, instead of contacting the nanotubes ends, the tip of our C-SFM does make contact perpendicularly to the lying MWCNTs sheets forming part of the percolated network. Different I-V responses in C-SFM have been reported for individual graphene sheets as well [26], where non-ohmic behaviour was attributed to the presence of graphitic domains separated by defect clusters, giving raise to hopping conduction as the dominant charge transport mechanism.

Therefore, C-SFM results strongly upholds the hypothesis previously presented that electrical current is supported by MWCNTs bundles located at grain boundaries, which present two types of conduction mechanisms: metallic-like and semiconductor. The metallictype one is associated to charge transport along the nanotube shells, whereas the semiconductor behaviour could be linked to hopping conduction across different potential barriers associated to the nanotube-nanotube contacts [15] and to intrinsic defect clusters within the nanotubes separating metallic domains. These barriers give two different relaxation phenomena in ac measurements. Intrinsic defects within nanotubes are formed in areas where twisting and bending occur, inducing strong modifications of their electronic structure and provoking metallic to semiconducting transitions, as shown recently by Giusca et al. [27]. The 
semiconducting mechanisms might become dominant if the conducting regions are not large enough. For the specimen with 0.9 vol\% of MWCNTs, hopping conduction associated to contacts between nanotubes would be the dominant charge transport mechanism at all temperatures. As nanotube content increases, defect clusters separating metallic domains along them, with smaller relaxation distances [27], would become significant. By increasing the temperature, the release of the nanotubes twist and collapse deformations would explain the transition from two to one R-C circuits observed at $473 \mathrm{~K}$. Startlingly, this temperature coincides with the annealing temperature for releasing of the Wigner energy (energy stored as crystalline dislocations induced by neutron irradiation in graphite). Moreover, thermal relaxation of intersticial-vacancy pair defects has also been observed at that temperature in double-walled carbon nanotubes [28].

Even though the study of mechanical properties of $\mathrm{Si}_{3} \mathrm{~N}_{4} / \mathrm{MWCNT}$ is not the scope of this paper, it can be said that for composites containing 1.8 vol\% of MWCNTs, the fracture toughness $\left(\mathrm{K}_{\mathrm{IC}}\right)$ is slightly higher than for blank $\mathrm{Si}_{3} \mathrm{~N}_{4}$ specimen of similar $\alpha / \beta$ phase ratio, 4.8 vs. 4.5 MPa $\mathrm{m}^{1 / 2}[12]$. Furthermore, ongoing studies show that these composite materials have a substantial improved response in terms of wear resistance, which is of great interest considering the real applications of $\mathrm{Si}_{3} \mathrm{~N}_{4}$ materials.

\section{Conclusions}

The multi-scale electrical behaviour response assembled by combining macroscopic electrical characterization and nanoscale C-SFM measurements describes a coherent picture of the dominant charge transport mechanisms in $\mathrm{Si}_{3} \mathrm{~N}_{4} / \mathrm{MWCNTs}$ composites. A balance between semiconductor and metallic-like mechanisms, whose weights depend on both the temperature and the MWCNTs content, is observed. The metallic-type conduction is associated to charge transport along the nanotube shells whereas the semiconductor behaviour is linked to hopping conduction across nanotube-nanotube contacts and across intrinsic defect 
clusters within the nanotubes separating metallic domains. When the MWCNTs network is close to the percolation ( 0.9 vol\% composite), inter-nanotubes hopping or tunnelling mechanisms become the rate limiting steps for charge transport. Once this concentration is surpassed the contribution of defect clusters within nanotubes in the highly conductive paths competes with the above mechanism. C-SFM measurements highlight that the high current and linear behaviour measured in outcropping nanotube clusters is due to conduction in the outermost shells, while lower current and non-linear behaviour is assessed when the contact is perpendicular to lying MWCNTs sheets of the percolated network.

\section{Acknowledgements}

The financial support of Spanish Ministry of Science and Innovation through projects MAT2006-7118, MAT2007-62732 and NANOSELECT CSD2007-00041 is recognized. J. Gonzalez-Julian acknowledges the financial support of the JAE (CSIC) fellowship Program and Y. Iglesias acknowledges the financial support of the FPI Program.

\section{References}

[1] Riley FL, Silicon nitride and related materials. J Am Ceram Soc 2000; 83(2): 245-265.

[2] Liu CC, Huang JL. Effect of the electrical discharge machining on strength and reliability of TiN/Si $\mathrm{N}_{4}$ composites. Ceram Int 2003; 29(6): 679-687.

[3] Guo Z, Blugan G, Graule T, Reece M, Kuebler J. The effect of different sintering additives on the electrical and oxidation properties of $\mathrm{Si}_{3} \mathrm{~N}_{4}-\mathrm{MoSi}_{2}$ composites. J Eur Ceram Soc 2007; 27(5): 2153-2161.

[4] Tatami J, Katashima T, Komeya K, Meguro T, Wakihara T. Electrically conductive CNTdispersed silicon nitride ceramics. J Am Ceram Soc 2005; 88(10): 2889-2893. 
[5] Zhan GD, Kuntz JD, Garay JE, Mukherjee AK. Electrical properties of nanoceramics reinforced with ropes of single-walled carbon nanotubes. Appl Phys Lett 2003; 83(6): 12281230.

[6] Balazsi Cs, Fenyi B, Hegman N, Kover Z, Weber F, Vertesy Z, Konya Z, Kiricsi I, Biro LP, Arato P. Development of $\mathrm{CNT} / \mathrm{Si}_{3} \mathrm{~N}_{4}$ composites with improved mechanical and electrical properties. Comp B 2006; 37(6): 418-424.

[7] Shi SL, Liang J. Effect of multiwall carbon nanotubes on electrical and dielectric properties of yttria-stabilized zirconia ceramic. J Am Ceram Soc 2006; 89(11): 3533-3535.

[8] Poorteman M, Traianidis M, Bister G, Cambier F. Colloidal processing, hot pressing and characterisation of electroconductive MWCNT-alumina composites with compositions near the percolation threshold. J Eur Ceram Soc 2009; 29(4): 669-675.

[9] Ahmad K, Pan W, Shi SL. Electrical conductivity and dielectric properties of multiwalled carbon nanotube and alumina composites. Appl Phys Lett 2006; 89(13): 133122.

[10] Rul S, Lefevre-Schlick F, Capria E, Laurent Ch, Peigney A. Percolation of single-walled carbon nanotubes in ceramic matrix nanocomposites. Acta Mater 2004; 52(4): 1061-1067.

[11] Flahaut E, Peigney A, Laurent Ch, Marliere Ch, Chastel F, Rousset A. Carbon nanotubemetal-oxide nanocomposites: Microstructure, electrical conductivity and mechanical properties. Acta Mater 2000; 48(15): 3803-3812.

[12] Osendi MI, Gautheron F, Miranzo P, Belmonte M. Dense and Homogenous Silicon Nitride Composites Containing Carbon Nanotubes. J Nanosci Nanotechnol 2009; 9(10): 6188-6194.

[13] Horcas I, Fernandez R, Gomez-Rodriguez JM, Colchero J, Gomez-Herrero J, Baro AM. A software for scanning probe microscopy and a tool for nanotechnology. Rev Sci Instrum 2007; 78: 013705 . 
[14] Munuera C, Barrena E, Ocal C. Scanning force microscopy three-dimensional modes applied to conductivity measurements through linear-chain organic SAMs. Nanotechnology 2007; 18(12): 125505.

[15] Li CY, Thostenson ET, Chou TW. Dominant role of tunneling resistance in the electrical conductivity of carbon nanotube-based composites. App Phys Lett 2007; 91(22): 223114.

[16] Nalwa HS. Handbook of low and high dielectric constant materials and their applications. Academic Press, 1999.

[17] Pike GE. Semiconductor grain-boundary admittance-theory. Phys Rev B 1984; 30(2): 795-802.

[18] Blatter G, Greuter F. Carrier transport through grain-boundaries in semiconductors. Phys Rev 1986; 33(6): 3952-3966.

[19] Mc Donald JR, Impedance Spectroscopy Theory, Experiment and Applications. Barsoukov E, editor. Wiley-Interscience, John Wiley \& Sons, Inc., Hoboken, New Jersey, 2005.

[20] Ahmad K, Pan W. Dramatic effect of multiwalled carbon nanotubes on the electrical properties of alumina based ceramic nanocomposites. Comp Sci Technol 2009; 69(7-8): 1016-1021.

[21] Ebbesen TW, Lezec HJ, Hiura H, Bennett JW, Ghaemi HF, Thio T. Electrical conductivity of individual carbon nanotubes. Nature 1996; 382(6586): 54-56.

[22] Kulesza S, Szroeder P, Patyk JK, Szatkowski J, Kozanecki M. High-temperature electrical transport properties of buckypapers composed of doped single-walled carbon nanotubes. Carbon 2006; 44(11): 2178-2183.

[23] Zhao YP, Wei BQ, Ajayan PM, Ramanath G, Lu TM, Wang GC, Rubio A, Roche S. Frequency-dependent electrical transport in carbon nanotubes. Phys Rev B 2001; 64(20): 201402. 
[24] Frank S, Poncharal P, Wang ZL, de Heer WA. Carbon nanotube quantum resistors.

Science 1998; 280(5370): 1744-1746.

[25] Tsukagoshi K, Watanabe E, Yagi I, Yoneya N, Aoyagi Y. Multiple-layer conduction and scattering property in multi-walled carbon nanotubes. New J Phys 2004; 6: 3.

[26] Gomez-Navarro C, Weitz RT, Bittner AM, Scolari M, Mews A, Burghard M, Kern K.

Electronic transport properties of individual chemically reduced graphene oxide sheets. Nano Lett 2007; 7(11): 3499-3503.

[27] Giusca CE, Tison Y, Silva SRP. Evidence for metal-semiconductor transitions in twisted and collapsed double-walled carbon nanotubes by scanning tunneling microscopy. Nano Lett $2008 ; 8(10): 3350-3356$.

[28] Urita K, Suenaga K, Sugai T, Shinohara H, Iijima S. In situ observation of thermal relaxation of interstitial-vacancy pair defects in a graphite gap. Phys Rev Lett 2005; 94(15): 155502. 


\section{Captions}

Figure 1. TEM micrograph for the composite containing 5.3 vol\% of MWCNTs. The nanotubes are pointed out by arrows. A MWCNTs bundle is shown marked with a "B". Figure 2. Measured dc conductivity as a function of MWCNTs content. Electrical conductivity values represent an average of at least three measurements with a standard deviation of $\sim 5 \%$.

Figure 3. Measured dc current-voltage data as a function of the temperature for the composites with (a) 0.9 and (b) 8.6 vol\% of MWCNTs.

Figure 4. Complex impedance measured at different temperatures for the specimens with (a) 0.9 and (b) 8.6 vol\% of MWCNTs.

Figure 5. Topographic $(\mathrm{a}, \mathrm{c})$ and C-SFM images at $\mathrm{V}_{\text {tip }}=1 \mathrm{~V}(\mathrm{~b}, \mathrm{~d})$ for the composites containing 0.9 vol\% $(a, b)$ and 5.3 vol\% $(c, d)$ of MWCNTs.

Figure 6. FESEM micrographs showing: a) polished and plasma etched surface corresponding to the composite containing 8.6 vol\% of MWCNTs and b) nanotubes outcropping at the fracture surface of the composite with 5.3 vol\% of MWCNTs. Arrows in (a) point nanotubes. Figure 7. C-SFM image at $\mathrm{V}_{\text {tip }}=1 \mathrm{~V}(\mathrm{a}), \mathrm{I}-\mathrm{V}$ curve at the outcropping MWCNTs (b) and merged topography plus C-SFM image (c) for the composite with 1.8 vol\% of MWCNTs. Figure 8. (a) Merged topography plus C-SFM image for the composite with 5.3 vol\% of MWCNTs, (b) current profile at Vtip $=1 \mathrm{~V}$ along the line drawn on the image, (c) and (d) are the I-V curves taken at regions of low and high current values, respectively. 


\section{ACCEPTED MANUSCRIPT}

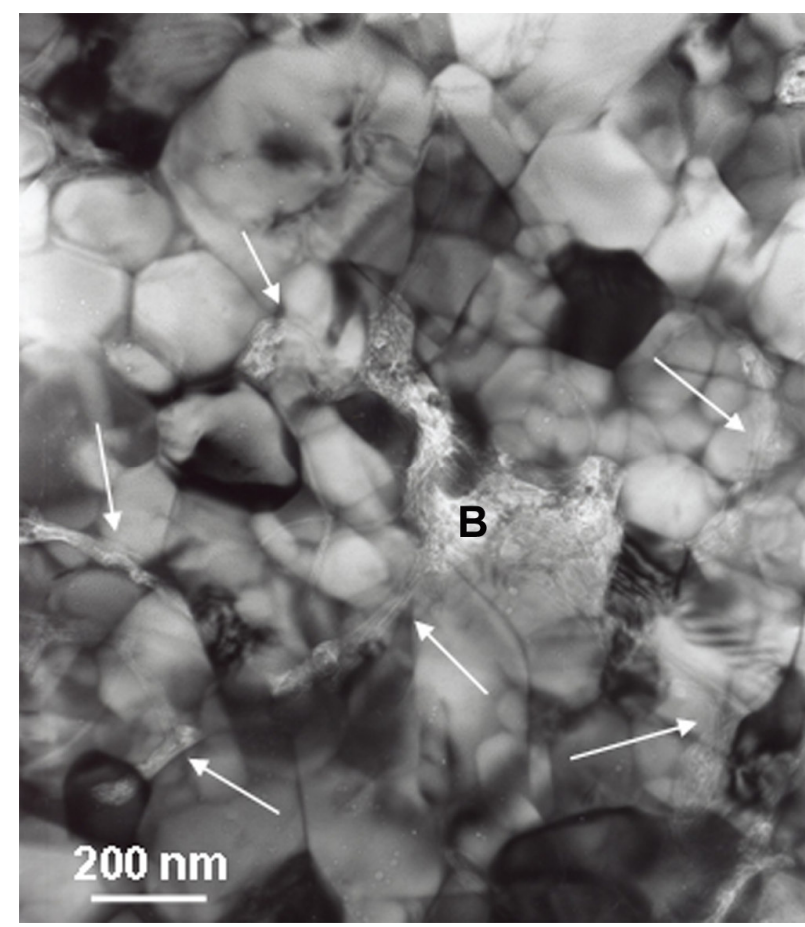




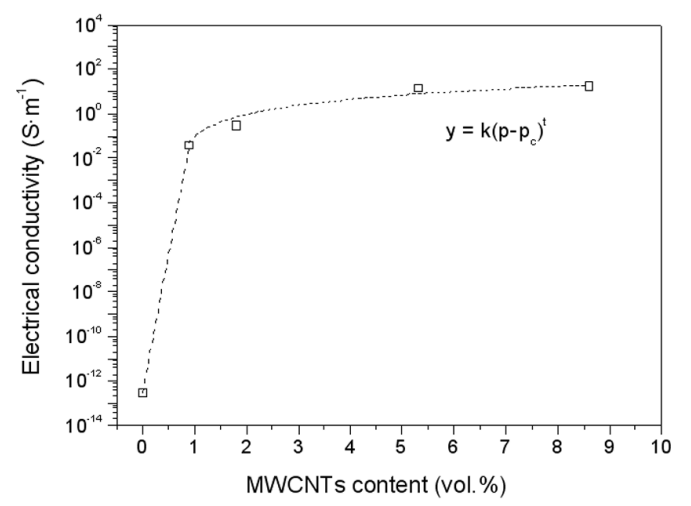



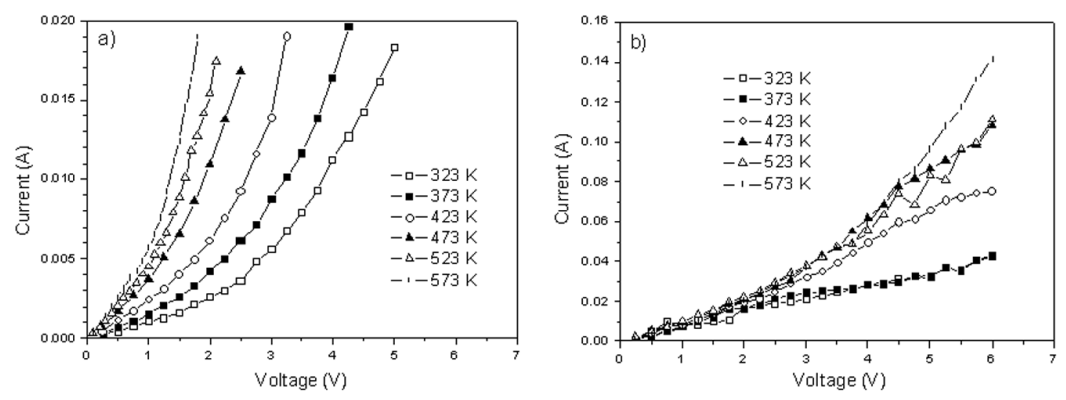

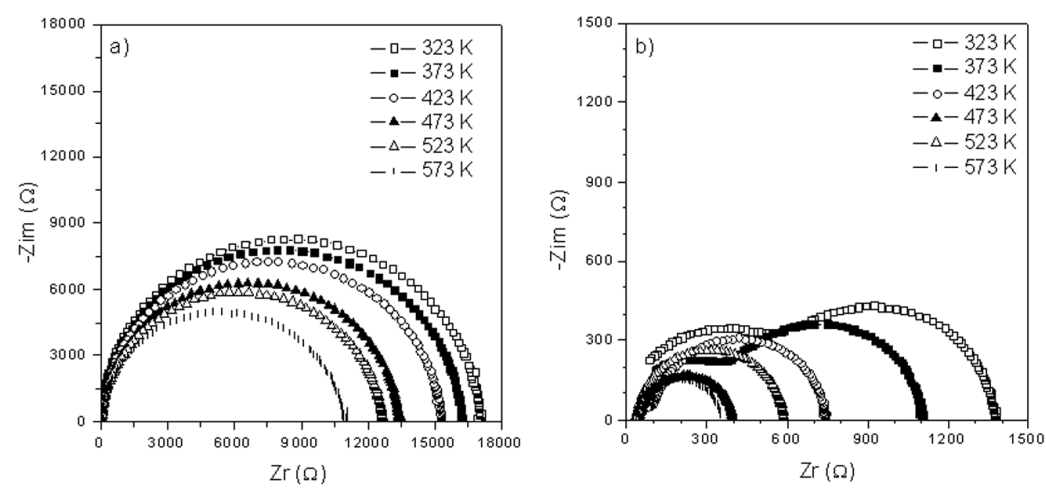

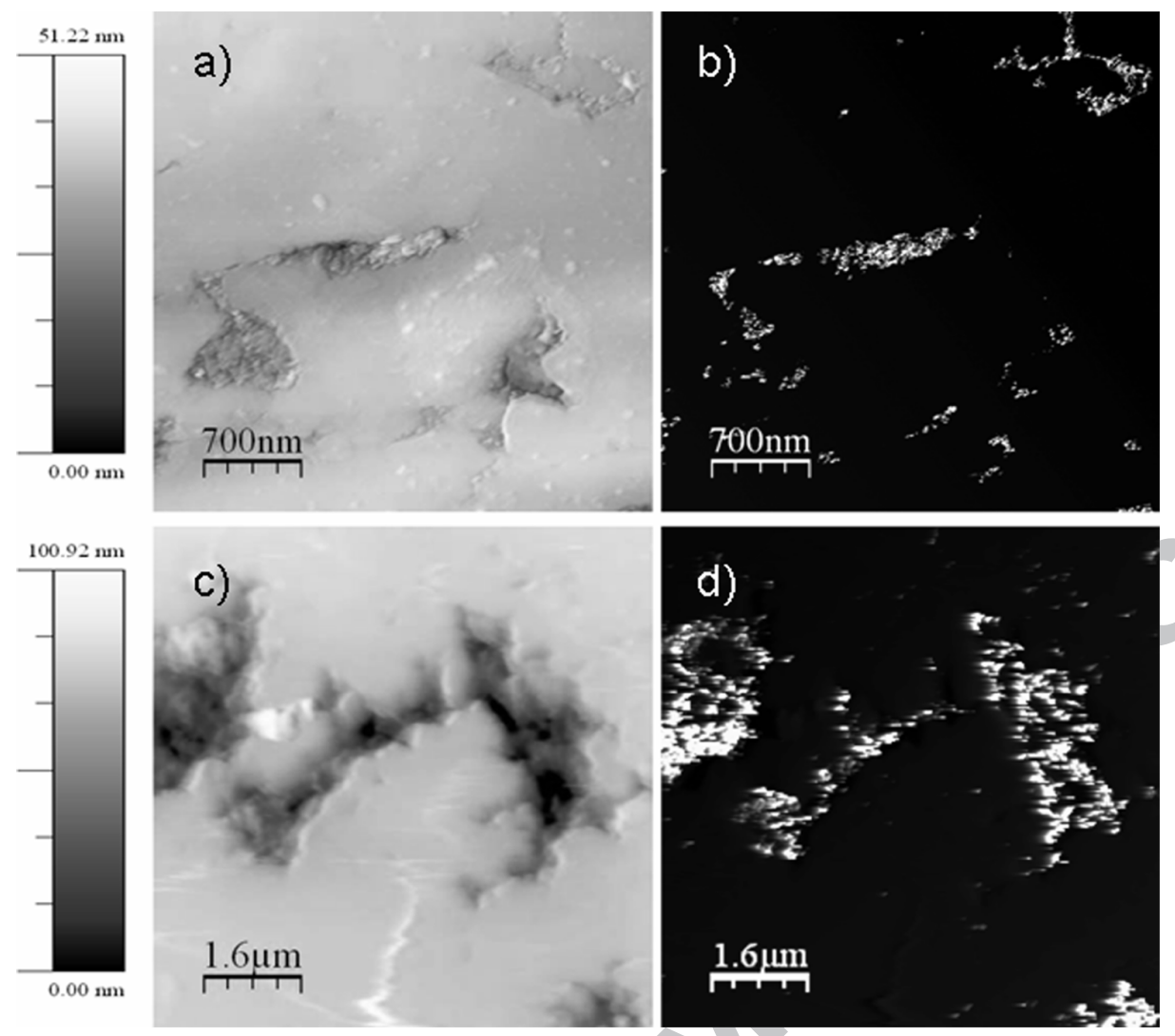

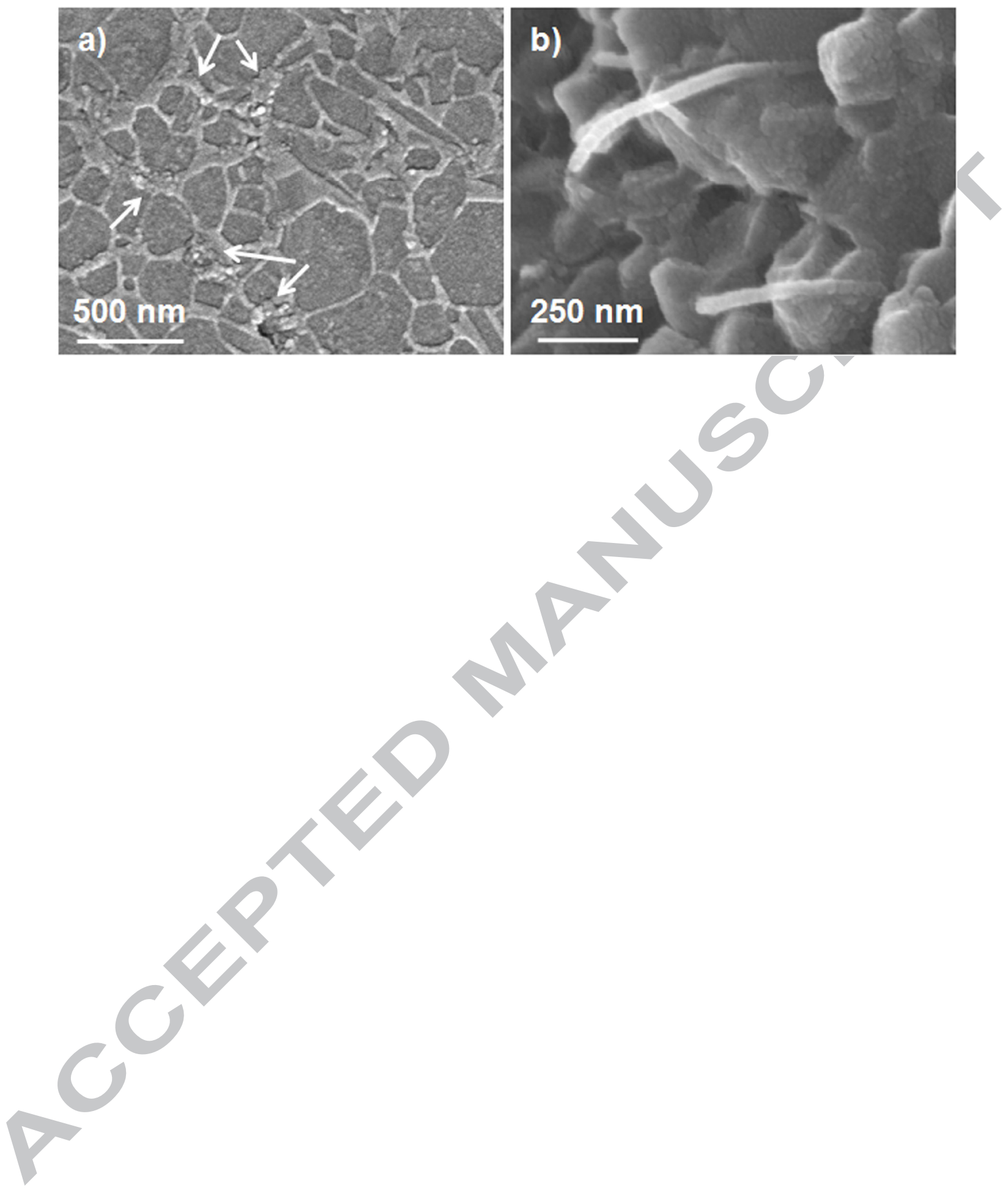


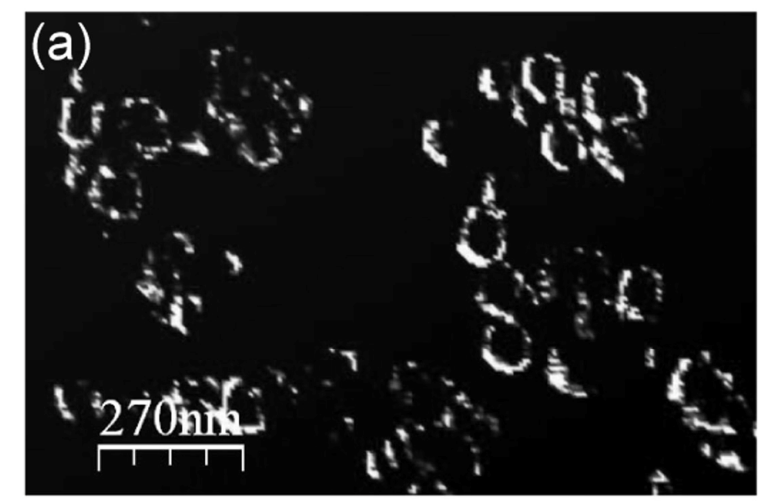

(b)
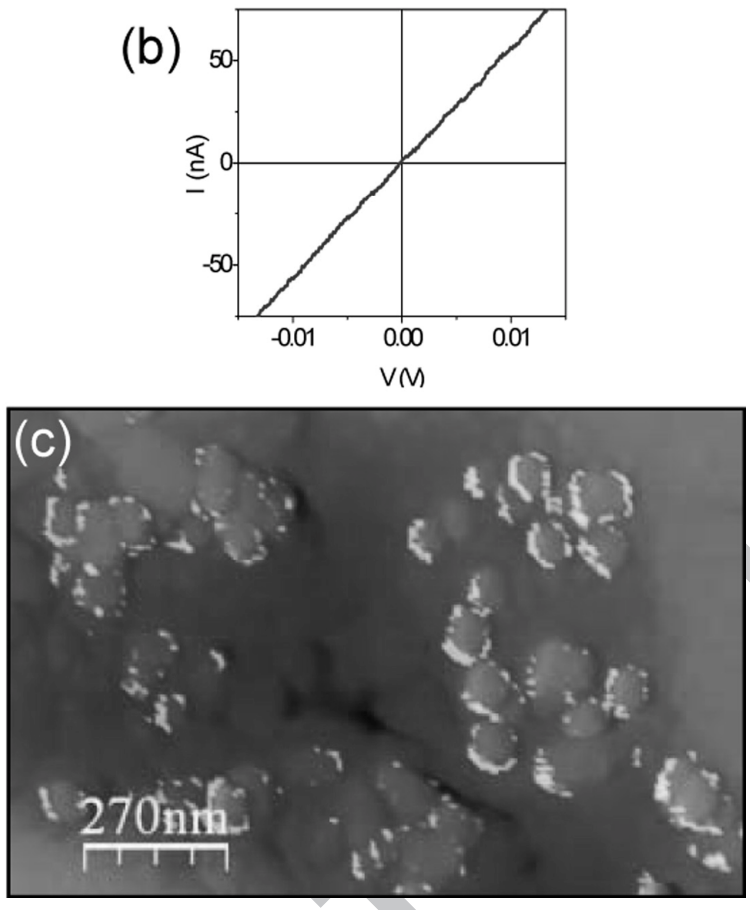

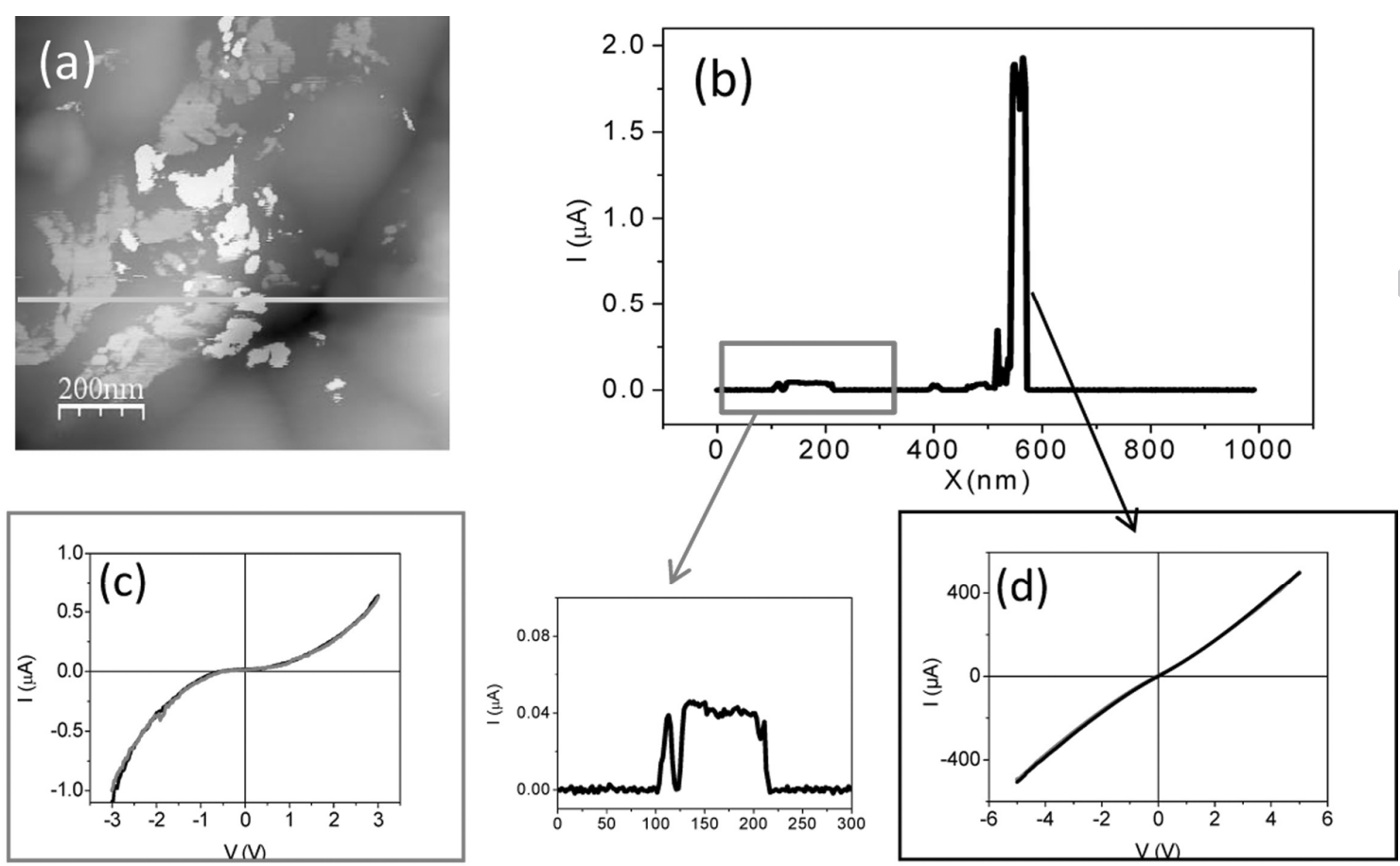